\title{
المسؤولية الاجتماعية كمتغير وسيط في العلاقة بين التشوهات المعرفية والتمرد النفسي لدي عينة من طالبات الجامعة
}

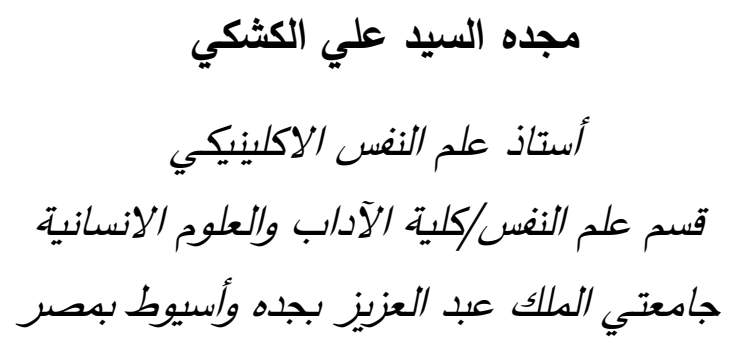

$$
\text { أستاذ علم النفس الاكلينيكي }
$$$$
\text { قسم علم النفس/كلية الآداب والعلوم الانسانية }
$$

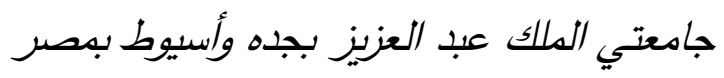

\author{
رضية محمد حميد الدين \\ أستاذ علم النفس المشارك

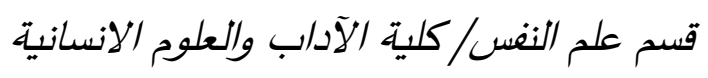 \\ جامعة الملك عبد العزيز
}

مستخلص. يُّكّن الأداء المعرفي الطبيعي الأفراد من ضمان الأداء الدقيق لعمليات التفكير المختلفة بما في ذلك تلقي

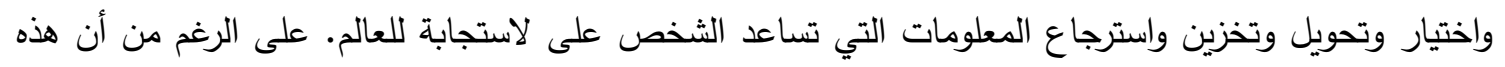

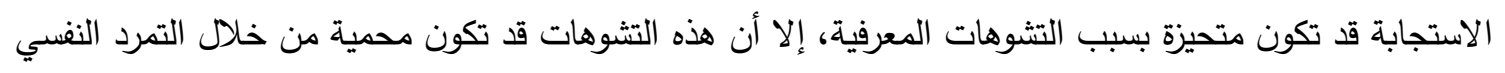

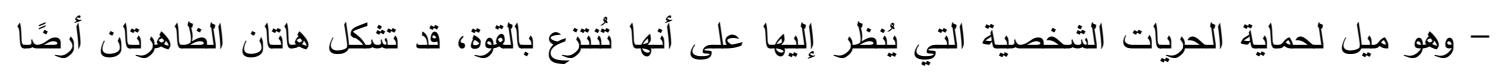
خصبة لتطوير الأمراض النفسية المختلفة، مما ييرز أهمية فهم علاقتهما.

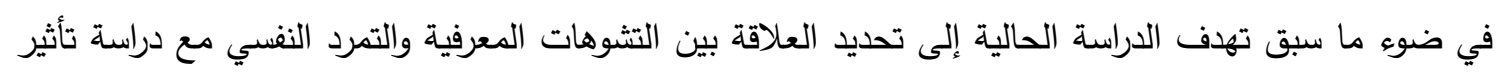
الكسؤولية الاجتماعية كمتغير وسيط في العلاقة بينهما.

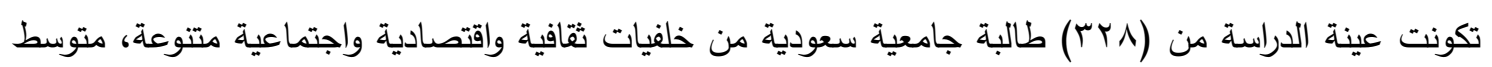

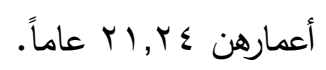
أظهرت النتائج انه يمكن التتبؤ بالتمرد النفسي من خلال التشوهات المعرفية، وأن الالتزام الاجتماعي كأحد أبعاد

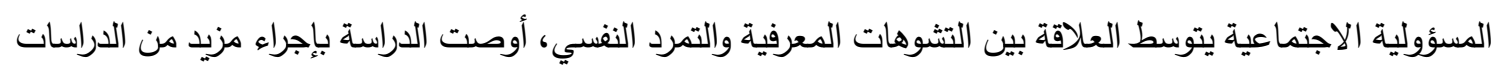
على عينات أكثر تمثيلا قبل تعميم هذه النتائج. الكلمات المفتاحية: التمرد النفسي، التثوهات المعرفية لدهن، المسؤولية الاجتماعية، طلاب الجامعة. 
Sternberg, R., \& Sternberg, K. (2016). Cognitive psychology. Nelson Education. Tajfel, H. (1974). Social identity and intergroup behaviour. Information (International Social Science Council), 13(2), 65-93.

Tennen, H., Press, S., Rohrbaugh, M., \& White, L. (1981). Reactance theory and therapeutic paradox: A compliancedefiance model. Psychotherapy: Theory, Research \& Practice, 18(1), 14-22.

Van Petegem, S., Soenens, B., Vansteenkiste, M., \& Beyers, W. (2015). Rebels with a cause? Adolescent defiance from the perspective of reactance theory and selfdetermination theory. Child Development, 86(3), 903-918.
Yakovenko, I., Hodgins, D., el-Guebaly, N., Casey, D., Currie, S., Smith, G., ... Schopflocher, D. (2016). Cognitive distortions predict future gambling involvement. International Gambling Studies, 16(2), 175-192.

Youssef, C., Casey, S., \& Day, A. (2016). Desistance: The "other side" of change and implications for maintenance programs. Journal of Offender Rehabilitation, 55(7), 443-465.

Yurica, C. (2002). Inventory of Cognitive Distortions: Development and validation of a psychometric test for the measurement of cognitive distortions (Doctoral dissertation, Philadelphia College of Osteopathic Medicine). 
of appeals to help unknown others through bone marrow donation. Human Communication Research, 31(4), 453481.

Ma, Y., Dixon, G., \& Hmielowski, J. (2019). Psychological reactance from reading basic facts on climate change: The role of prior views and political identification. Environmental Communication, 13(1), 71-86.

Miguel, F., \& Pessotto, F. (2016). Projective aspects on cognitive performance: distortions in emotional perception correlate with personality. Psicologia: Reflexão e Crítica, 29(1), 17.

Morrison, A., Potter, C., Carper, M., Kinner, D., Jensen, D., \& Heimberg, R. (2015). The Cognitive Distortions Questionnaire (CD-Quest): psychometric properties and exploratory factor analysis. International Journal of Cognitive Therapy, 8(4), 287305.

Mullen, B., Brown, R., \& Smith, C. (1992). Ingroup bias as a function of salience, relevance, and status: An integration. European Journal of Social Psychology, 22(2), 103-122.

Najavits, L., Gotthardt, S., Weiss, R., \& Epstein, M. (2004). Cognitive distortions in the dual diagnosis of PTSD and substance use disorder. Cognitive Therapy and Research, 28(2), 159-172.

Nisbett, R., \& Wilson, T. (1977). The halo effect: evidence for unconscious alteration of judgments. Journal of personality and social psychology, 35(4), 250-256.

Revelle, W. (2018). psych: Procedures for personality and psychological research Evanston. Illinois: Northwestern University.

Rnic, K., Dozois, D., \& Martin, R. (2016). Cognitive distortions, humor styles, \& depression. Europe's journal of psychology, 12(3), 348-362.
O’Toole, M.S., Mennin, D.S., Hougaard, E. , Zachariae, R7\& Rosenberg., N.K.(2015).Cognitive and emotion regulation change processes in cognitive behavioural therapy for social anxiety disorder .Clin Psychol Psychother, 22(6), 667-676.

Passini, S., \& Morselli, D. (2009). The obedience-disobedience dynamic and the role of responsibility. Journal of Community \& Applied Social Psychology, 20(1), 1-14.

Roberts, M. (2014). Inventory of cognitive distortions: Validation of a measure of cognitive distortions using a community sample. Psychology.

Rosseel, Y. (2012). Lavaan: an R package for structural equation modeling. Journal of Statistical Software, 48(2), 1-36.

Rutter, J., \& Friedberg, R. (1999). Guidelines for the effective use of Socratic dialogue in cognitive therapy. Innovations in clinical practice: A source book, 17, 481490.

Samoilov, A., \& Goldfried, M. (2000). Role of emotion in cognitive-behavior therapy. Clinical Psychology: Science and Practice, 7(4), 373-385.

Siegel, J., Lienemann, B., \& Rosenberg, B. (2017). Resistance, reactance, and misinterpretation: Highlighting the challenge of persuading people with depression to seek help. Social and Personality Psychology Compass, 11(6), e12322.

Smith, H., \& Tyler, T. (1997). Choosing the right pond: The impact of group membership on self-esteem and grouporiented behavior. Journal of experimental social psychology, 33(2), 146-170.

Stallard, P. (2019). Think Good, Feel Good: A Cognitive Behavioural Therapy Workbook for Children and Young People. Wiley. 
pretentiousness, immorality, and Machiavellianism. Journal of Personality Disorders, 24(2), 244-257.

Dillard, J., \& Shen, L. (2005). On the nature of reactance and its role in persuasive health communication. Communication Monographs, 72(2), 144-168.

Dowd, E. (2016). Resistance and the wounded self: self-protection in service of the ego. American Journal of Clinical Hypnosis, 59(1), 100-113.

Ertmer, P., \& Newby, T. (1993). Behaviorism, cognitivism, constructivism: Comparing critical features from an instructional design perspective. Performance improvement quarterly, 6(4), 50-72.

Fang, S., \& Chung, M. (2019). The impact of past trauma on psychological distress among Chinese students: The roles of cognitive distortion and alexithymia. Psychiatry research, 271, 136-143.

Fenn, K., \& Byrne, M. (2013). The key principles of cognitive behavioural therapy. InnovAiT, 6(9), 579-585.

Flick, U. (2015). Introducing research methodology: A beginner's guide to doing a research project. Sage.

Folger, R., Ganegoda, D., Rice, D., Taylor, R., \& Wo, D. (2013). Bounded autonomy and behavioral ethics: Deonance and reactance as competing motives. Human Relations, 66(7), 905-924.

Gardner, L., \& Leshner, G. (2016). The role of narrative and other-referencing in attenuating psychological reactance to diabetes self-care messages. Health communication, 31(6), 738-751.

Goddard, M. (2017). The contribution of psychological reactance to war entry. Peace and conflict: journal of peace psychology, 23(2), 189.

Gramann, J., Bonifield, R., \& Kim, Y. (1995). Effect of personality and situational factors on intentions to obey rules in outdoor recreation areas. Journal of Leisure Research, 27(4), 326-343.

Harrell Jr, Frank E, with contributions from Charles Dupont, and many others(2019). Hmisc: Harrell Miscellaneous. https://CRAN.Rproject.org $/$ package $=$ Hmisc.

Hong, S., \& Page, S. (1989). A psychological reactance scale: Development, factor structure and reliability. Psychological Reports, 64(3_suppl), 1323-1326.

Johnson, M., Sacks, D., \& Edmonds, W. (2010). Counseling athletes who use performance-enhancing drugs: A new conceptual framework linked to clinical practice. Journal of Social, Behavioral, and Health Sciences, 4(1), 1-29.

Jonason, P., \& McCain, J. (2012). Using the HEXACO model to test the validity of the Dirty Dozen measure of the Dark Triad. Personality and Individual Differences, 53(7), 935-938.

Jorgensen, T. D., Pornprasertmanit, S., Schoemann, A. M., \& Rosseel, Y. (2018). semTools: Useful tools for structural equation modeling (version 0.5-0) [Computer software]. Retrieved from https://CRAN.Rproject.org $/$ package $=$ semTools

Joshi, A., \& Phadke, K. (2018). Rational Emotive Behaviour Therapy Integrated. SAGE Publishing India.

Ladouceur, R., Rhéaume, J., \& Aublet, F. (1997). Excessive responsibility in obsessional concerns: A fine-grained experimental analysis. Behaviour Research and Therapy, 35(5), 423-427.

Lewing, C. (2005). Psychopathy as a moderator of the relationship between psychological reactance and sexual assault acceptance and perpetration among incarcerated and non-incarcerated males. University of South Dakota.

Lindsey, L. (2005). Anticipated guilt as behavioral motivation: An examination 
Conclusion

The results of this study confirmed the relationship between cognitive distortions (from the anxious and depressive spectrum of mental health disorders) and psychological reactance, with more distortions being related to more reactance. Components of responsibility - individual responsibility, social obligation and social reaction - were tested as the potential mediators of this relationship. Only social obligation was found as a partial mediator for the distortion-reactance relationship, while individual responsibility and social reaction served as suppressors. Another relevant finding of this study was that the factor structures of the applied questionnaires did not match those obtained in the earlier literature, which may be attributed to different statistical approaches, cultural differences or the use of a non-representative sample. Taking into account its limitations, this study has provided a valuable contribution to the exploration of the relationship between cognitive distortion, psychological reactance and responsibility and may serve as a stepping-stone to a new line of studies that may result in more effective treatment of both internalized and externalized problems.

Acknowledgments

This project was funded by the Deanship of Scientific Research (DSR), at King Abdulaziz University, Jeddah, under grant no. (Z: 8-24640). The authors, therefore, acknowledge with thanks the DSR for their technical and financial support.

References

Alford, B. \& Beck, A. (1994). Cognitive therapy of delusional beliefs. Behaviour Research and Therapy, 32(3), 369-380.

Amone-P'Olak, K. Boitumelo, V. \& Mberengwa, D. (2019). Cognitive emotion regulation strategies and mental health problems in war-affected youth in Northern Uganda: findings from the
WAYS study. Journal of Mental Health, 28(2), 125-131.

Biggs, M. (2009). Self-fulfilling prophecies. The Oxford handbook of analytical sociology, 294-314.

Brehm, J.. (1966). A theory of psychological reactance. Oxford, England: Academic Press.

Borum,R.(2003).Understanding the terrorist mindset. FBI Law Enforcement Bulletin, 72(7),7-10.

Brown, M., Serovich, J., Kimberly, J. \& Hu, J. (2016). Psychological reactance and HIV-related stigma among women living with HIV. AIDS care, 28(6), 745-749.

Brosseau-Liard, P., \& Savalei, V. (2014). Adjusting incremental fit indices for nonnormality. Multivariate Behavioral Research, 49(5), 460-470.

Bulmer, M. (2015). The social basis of community care (Routledge Revivals). Routledge.

Burton, S., Cook, L., Howlett, E., \& Newman, C. (2015). Broken halos and shattered horns: overcoming the biasing effects of prior expectations through objective information disclosure. Journal of the Academy of Marketing Science, 43(2), 240-256.

Chambers, J., Eccleston, L., Day, A., Ward, T., \& Howells, K. (2008). Treatment readiness in violent offenders: The influence of cognitive factors on engagement in violence programs. Aggression and Violent Behavior, 13(4), 276-284.

Clayton, R., Lang, A., Leshner, G., \& Quick, B. (2019). Who fights, who flees? An integration of the LC4MP and psychological reactance theory. Media Psychology, 22(4), 545-571.

De Vries, R., \& van Kampen, D. (2010). The HEXACO and 5DPT models of personality: A comparison and their relationships with psychopathy, egoism, 
somewhat unexpected results. One effect (social obligation) turned out to be a partial mediation, while the other two (individual responsibility and social reaction) served as suppressors. This means that the relationship between cognitive distortions and psychological reactance can partially be explained by social obligation, defined in terms related social participation and cooperation. However, individual responsibility, defined in terms related to one's own responsibilities, and social reaction, defined in terms of the tendency to solve other peoples' problems, can be used to partially increase the variance in both cognitive distortions and psychological reactance to obtain a stronger and clearer relationship between the two concepts. While the latter two effects have more statistical than theoretical meaning, the former mediation effect found is not surprising. From a wider perspective, psychological reactance can be observed as a foundation of rebellious behaviours (Brehm, 1966), which makes it a counterpart of socially desirable behaviours and traits (Passini \& Morselli, 2009). Socially responsible individuals are also more likely to behave prosocially and conform to social norms (Gramann, Bonifeld \& Kim, 1995). Therefore, it is not unusual to find that at least one part of the relationship between cognitive distortions and psychological reactance can be attributed to (pro)social behaviours. However, the finding of partial mediation implies that a large amount of covariation between psychological reactance and cognitive distortions remains unexplained by the components of social responsibility. One potential candidate for this could be dark personality traits like psychopathy, which is known for antisocial behaviours (de Vries \& van Kampen, 2010; Jonason \& McCain, 2012, Lewing, 2005). Therefore, in future studies it may also be relevant to include some personality measures to assure that the outcomes are not biased by fundamental constructs like personality traits.
Another finding that makes this research relevant is that the factor structures of the applied questionnaires, are different from the previous ones (Roberts, 2014, Hong \& Page, 1989). Although this could be attributed to the specificity of the sample and one might hypothesize that the factor structure would be similar to the ones found in the previous study if both men and women were included in the research, these findings may also imply cultural differences, as none of these scales were created in Saudi Arabia. Therefore, in any upcoming studies it would be advisable to use instruments that were developed specifically in the context that participants live in who are expected to solve them, as this could improve the construct validity of the study. Also, although this study revealed adequate internal consistency of the applied scales and stable factor structure, in order to assure that they measure exactly what they are supposed to measure further validation studies focused on convergent and divergent validity (multi-trait-multi-method studies) should be conducted, since multiple measures of both psychological reactance (Dillard \& Shen, 2005; Lindsey, 2005) and cognitive distortions (Morrisson et al., 2015) exist.

Also, while this study is closely focused on psychological phenomena, it would be interesting to use more behavioural measures of psychological reactance (e.g., how often it occurs or how intensive it gets) in order to grasp the concepts from a broader scope than just measuring related attitudes. Although this step may represent a big challenge to research, the quality of the behavioural findings might complement the existing literature based on emotional and cognitive processes, and thus lead to causal designs that might allow us to predict the amount of reactance from the intensity of distortions, or vice-versa, in order to create more effective treatments for issues that deteriorate mental health and, consequently, wellbeing in general. 
and cognitive distortions followed by the positive relationships between the individual and social reaction and psychological reactance lead to strengthening of the relationship between cognitive distortions and psychological reactance. This is also supported by the significant indirect paths through social obligation $(\mathrm{z}=2, \mathrm{p}=0.046)$ and social reaction $(\mathrm{z}=-2.06, \mathrm{p}$ $=0.039)$ and almost significant indirect path through individual responsibility $(\mathrm{z}=-1.83, \mathrm{p}=0.067)$. Therefore, the latter two indirect effects served as suppressors, while the first one appeared to be a partial mediator of the relationship between cognitive distortions and psychological reactance.

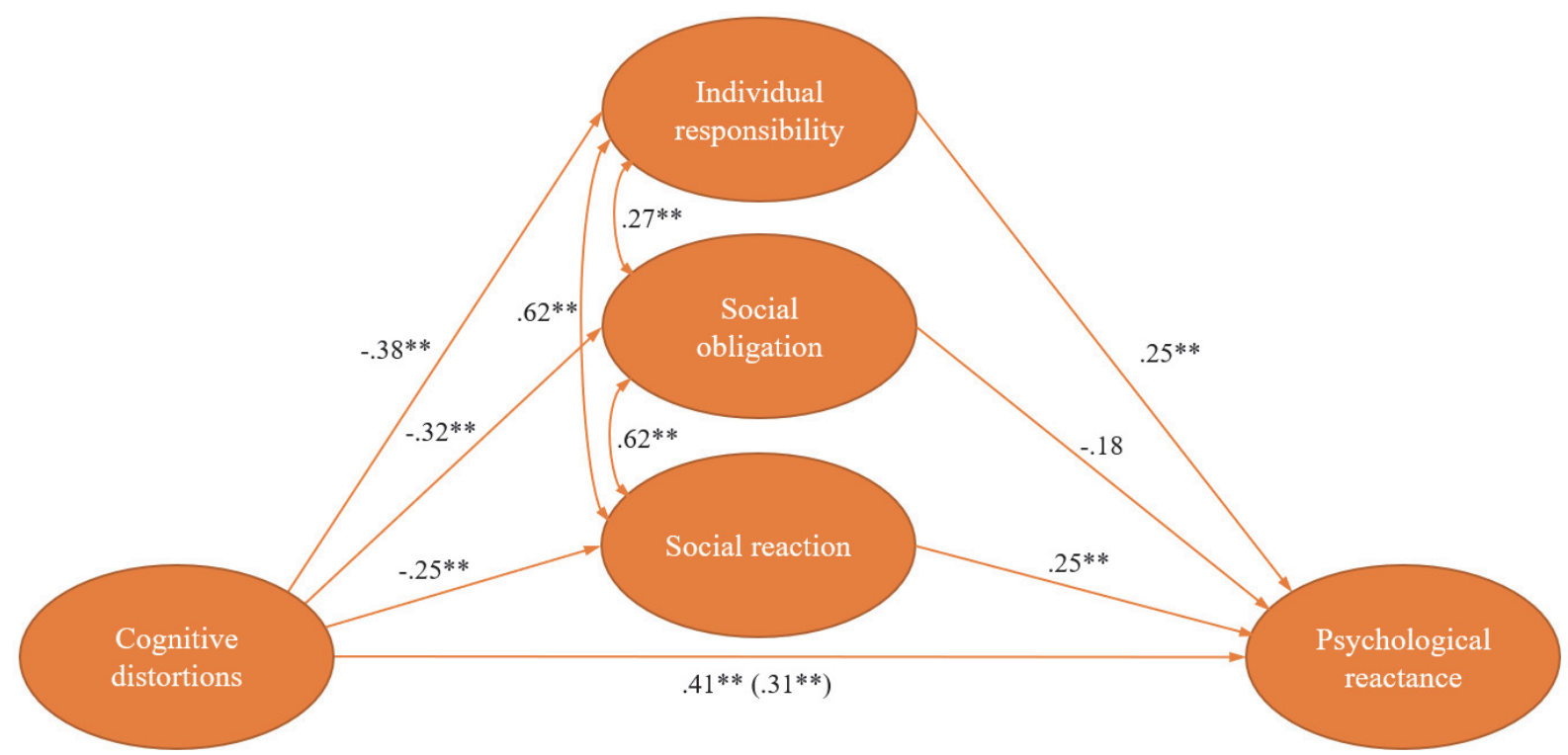

Note: items and error terms were omitted from this model for clarity

Figure 2. Standardized coefficients of cognitive distortions as predictors of psychological reactance mediated by social responsibility in a female Saudi sample $(\mathrm{N}=313)$

Discussion

The results of this study revealed several interesting findings. In relation to the first research question, the correlation matrix revealed that cognitive distortions are positively related to psychological reactance. This is in line with the discussions of previous authors on how to deal with the complex relationships among these phenomena (Siegel et al, 2017; Dowd, 2016; Alford \& Beck, 1994), as well as other studies that were focused on the relationship between cognitive distortions and rebellious behaviours (Joshi \& Phadke, 2018; Youssef, Casey \& Day, 2016). This relationship was found to be weak-to-moderate, regardless of the application of the non-normality correction. However, the notion of cognitive distortions in this study was comprised of distortions stemming from the anxious and depressive spectrum of disorders (Roberts, 2014). Therefore, it is crucial to interpret the results only in the context of those distortions, as more severe ones, including psychotic and/or paranoid distortions, might show stronger relationships with psychological reactance, which makes them relevant additional candidates for future studies. Nevertheless, this study highlighted the covariation between cognitive distortions (on the anxious and depressive spectrum) and psychological reactance in the sample of healthy, young participants, and thus represents the first step towards testing more complex causal models. In relation to the second research question, focused on the mediators of the distortionsreactance relationship, the research yielded 
Table (1) Correlations between cognitive distortions, psychological reactance and components of social responsibility (with Bonferroni correction for multiple comparisons)

\begin{tabular}{|l|l|l|l|l|l|}
\hline & $(1)$ & $(2)$ & $(3)$ & $(4)$ & $(5)$ \\
\hline (1) Psychological reactance & 1 & $0.28^{* *}$ & 0.11 & 0.16 & -0.09 \\
\hline (2) Cognitive distortions & & 1 & $-0.34^{* *}$ & $-0.22^{* *}$ & $-0.22^{* *}$ \\
\hline (3) Individual responsibility & & & 1 & $0.53^{* *}$ & $0.28^{* *}$ \\
\hline (4) Social obligation & & & & 1 & $0.42^{* *}$ \\
\hline (5) Social reaction & & & & & 1 \\
\hline
\end{tabular}

$* \mathrm{p}<0.05, * * \mathrm{p}<0.01$
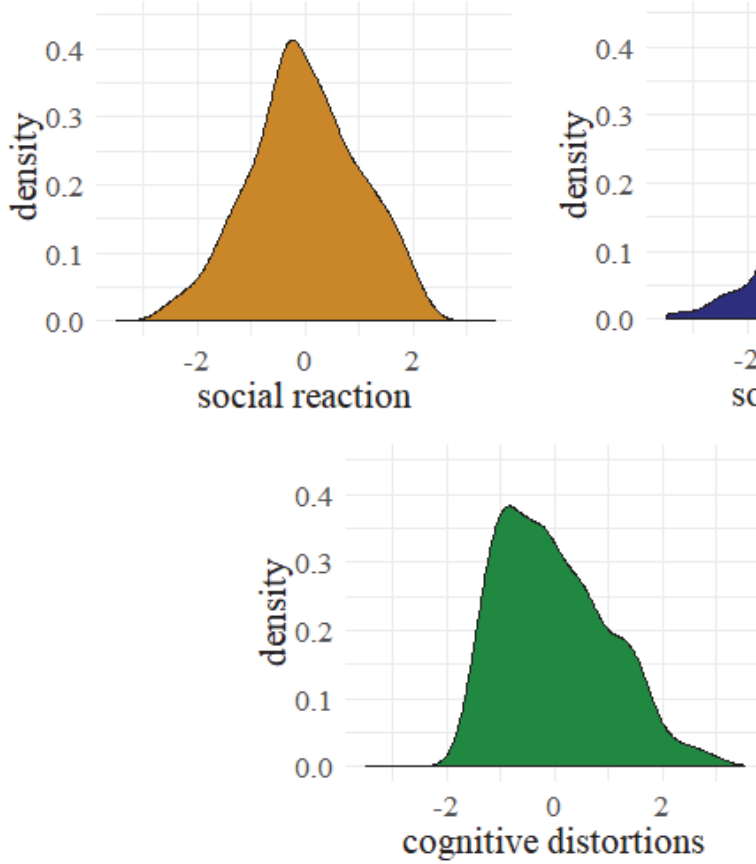
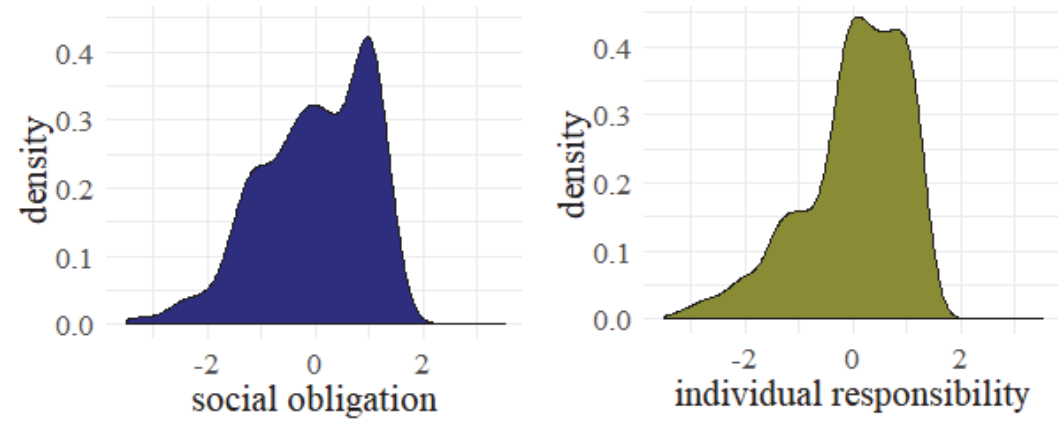

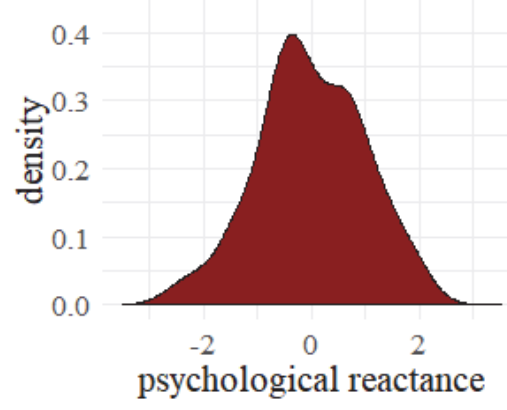

Figure 1. Distributions of component scores for the three components of social responsibility (social reaction, social obligation and individual responsibility), cognitive distortions and psychological reactance

After observing the initial results in 1 Table of correlation, SEM was conducted in order to see if the relationship between cognitive distortions and psychological reactance is mediated by the components of social responsibility.

The Figure 2 model, shown in its abbreviated form, was formed on the basis of the variables and factor structures exhibited in the previous section and tested using the robust version of Maximum likelihood estimate (Brosseau-Laird \& Savalei, 2014). The data confirmed the adequacy of the proposed model $\left(\chi^{2} / \mathrm{df}=2.12\right.$, robust RMSEA $=0.056$, SRMR $\left.=0.079\right)$, along

with the positive relationship between the cognitive distortions and psychological reactance. However, the Figure 2 model also shows that this effect became stronger when additional variables (potential mediators) were included. The negative relationship between the responsibility variables 
and aetiology of emotional disorders (related to anxiety and depression). The scale used was also based on the 5 point Likert scale where 1 represented strong option disagreement while 5 represented strong agreement. Since Roberts's previous attempt failed to replicate one third of the theoretical factors (Roberts, 2014) this scale was not used here. The principal component analysis of the data using the MAP test as the criterion for the optimal number of factors obtained in the Saudi sample indicated that two factors are sufficient to explain its underlying structure. In line with the previous analyses, items with low factor loadings and crossloadings were excluded from the second round of PCA, which was used to obtain the factor scores. The first, larger component consisted of 32 items and was named negative Selfperception (Cronbach $\alpha=0.96$ ), while the other factor consisted of seven items reflecting Perfectionism (Cronbach $\alpha=0.85$ ).

Data Collection

The purposive sampling technique, a type of non-probability technique, was used in order to collect the data from the participants. In this study, the number of participants is sufficient for collecting valuable information and generating authentic results using analytical methods like the structural equation modelling. The questionnaires were administered online. No reward system was used to motivate people to participate in the research. The study met all the required social and ethical standards as it is the prime responsibility of the researcher to fulfil the ethical requirements that include confidentiality, anonymity and autonomy (Flick, 2015). The participants were informed about the significance and purpose of conducting the research and both written and verbal consent were taken prior to recording their responses. Moreover, participants were $a b$ to make the decision to withdraw from the study at any moment.

$\mathrm{R}$ was used as the main analytical tool in this study. More specifically, packages lavaan
(Rosseel, 2012), semTools (Jorgensen et al., 2018), Hmisc (Harrell, 2019) and psych (Revelle, 2018) were used to carry out the structural equation modelling and all the related analyses.

Results

This section briefly presents the findings of the applied structural equation modelling. Firstly, the table of correlations based on the extracted component scores is presented and briefly discussed, followed by the Structural Equation Model.

The data (in Table 1) confirms the relationship between psychological reactance and cognitive distortions, as participants who exhibited higher levels of cognitive distortions also exhibited a higher level of psychological reactance. Distortions were also shown to be negatively related to the components of social responsibility, with more responsible individuals showing less cognitive distortion. Finally, the three components of social responsibility were highly correlated among themselves, although their relationship with psychological reactance failed to reach the threshold of significance. One of the potential reasons for this may lie in non-normal distribution of scores (Figure 1), which makes it relevant to use a version of SEM estimator robust to deviations from normality. 
objectives. The study was conducted within the setting of Saudi Arabian universities, with students being selected as its research population. A positivistic approach was used in the creation of this study. It was conducted as a cross-sectional design focused on the student population. This type of study design, also known as a "snapshot" study, is conducted for observational purposes, in which the data is gathered and analysed in a specific time frame, which prevents establishing any true causal relationships between the observed phenomena. Participants

The time frame for data collection and analysis was 8 months (February-September 2019), during which Saudi Arabian Universities were visited to gather the data on students within the age limit of 19-27 years. During this time frame, 328 female participants voluntarily completed the questionnaire. After excluding participants with invalid responses, 313 participants remained in the study. On average they were 21.24 years old $(\mathrm{SD}=2.13) .28 .4 \%$ of participants stated their income was below 5000 riyal, $35.4 \%$ of them that it was between 5000 and $10 \quad 000$ riyal, while $36.3 \%$ of participants stated their family income was above 10000 riyal. The majority of participants $(87.5 \%)$ had never been never married.

Measures

\section{1- Social Responsibility Scale}

The social responsibility scale in this research was formulated by the researchers for the purposes of this study. The scale comprised of 22 items. Each item was measured on the 5point Likert scale where 1 represented the strongly disagree option and 5 represented the strongly agree option. The principal component analysis with MAP criterion for the optimal number of factors conducted on this scale yielded a three-factor solution. From this solution, only variables that loaded over 0.30 on at least one factor and with difference in loading of 0.30 between the dominant and following loading were retained, and another principal component analysis was conducted on these items in order to get theoretically cleaner factors and results. The first factor, named individual responsibility (defined in terms related to one's own responsibilities), consisted of seven items (Cronbach $\alpha=0.87$ ), the second factor, named social obligation (social participation and cooperation), consisted of six items (Cronbach $\alpha=0.74$ ), while the third factor, named social reaction (defined in terms of the tendency to solve other peoples' problems), consisted of four items (Cronbach $\alpha$ $=0.89$ ).

2- Hong Psychological Reactance Scale

In reactance literature, the Hong Psychological Reactance Scale (Hong \& Page 1989) is known as one of the major steps in psychological research, so it was chosen as a measure of reactance for this study. The 14 items of its scale were presented as a 5-point Likert scale where 1 represented strong option disagreement, while 5 represented strong agreement. While Hong and Page (1989) found a four-factor structure of reactance using a factoring method that would nowadays be considered suboptimal, the principal component analysis with MAP test of the data obtained in the Saudi sample indicated that a single factor was sufficient. Similar to the previous scale, items with factor loadings below 0.30 were excluded from the second round of principal component analysis, which revealed a stable and adequately reliable (Cronbach $\alpha=0.77$ ) 11-item structure.

3- Inventory of Cognitive Distortions

The Inventory of Cognitive Distortions (ICD, Yurica, 2002) has been considered as the measure to use and design for in order to identify the categorical and distinctive use of cognitive distortions (Yurica, 2002). According to Roberts (2014), the development of this scale was based on cognitive theory in which these distortions play a vital role in the progression 
Dowd (2016) also discussed the relationship between "the wounded self" and reactance, focusing on this relationship in the context of anxiety, depression and anger. On the other hand, Siegel, Lienerman and Rosenberg (2017) highlighted that psychological reactance may undermine the motivation of individuals with deteriorated mental health to even seek help, indicating the complex network of cognitive distortions and reactance that prevent those who need help from asking for it. Rutter and Friedberg (1999), therefore, suggested the use of "Socratic dialogue" in cognitive therapy. This idea relies on the interrogative approach of the Socratic dialogue - while the therapist simply leads the client to reach his or her own conclusions, thus allowing reality testing, potential insights into cognitive distortions, reaching one's own conclusion and bypassing reactance. Similarly, Dowd (2016) discussed the use of the cognitive hypnotherapy model in treatment of cognitive distortions underlying mental health-related issues, and proposed hypnotherapy as a potential solution when a client is unable to bypass reactance. Ali (2018) also noticed that individuals too young to grasp the complexity of the world may be more prone to both distortions as a method of simplifying reality and reactance as a way of dealing with emotions related to unpleasant events, while Miguel and Pessoto (2016) pointed out that cognitive distortions at young age may even lead to altered development of personality. Taken together, these researchers, dominantly from a therapeutic perspective, support the notion of the relationship between reactance and distortions - regardless of whether the distortions created the reactance or the reactance led to the distortions. Outside the context of therapy, Johnson, Sacks and Edmonds (2010) highlighted the relevance of bypassing reactance while conducting antidoping campaigns among athletes, while emphasising the relevance of studying cognitive distortions as factors that may spur its development. Chambers, Eccleston, Day, Ward and Howells (2008) also discussed dysfunctional self-centred beliefs and their contribution to violent offending.

However, reactance also has a counterpart deonance, which is related to moral norms (Folger, Ganegoda, Rice, Taylor \& Wo, 2013). In brief, while reactance represents a tendency to behave in a way that reclaims personal freedom, deonance represents the tendency to behave in a morally upright manner. Therefore, deonance also conveys a dose of responsibility for one's own action in the context of wellbeing of other people, which implies limitations to the personal freedoms (Folger et al., 2013). The juxtaposition of reactance and deonance also implies that individuals high on deonance should be below average on reactance, although empirical proofs of this relationships are still scarce. One of the main concepts underlying deonance is responsibility for one's own actions and their consequences. Responsibility, on the other hand, in its excessive form is a known correlate of cognitive distortions related to obsessive-compulsive disorder (Najavits, Gotthardt, Weiss \& Epstein, 2004; Ladouceur, Rheaume \& Aublet, 1997), and exaggerated responsibility for unpleasant events to cognitive distortions is also related to depression and PTSD. From a theoretical perspective, it seems as if the responsibility should at the same time be negatively related to reactance and positively to cognitive distortions from the depressive spectrum. As such, different dimensions of responsibility may serve as mediators of the relationship between cognitive distortions and psychological reactance. Lack of empirical evidence about such relationships served as a motivation for conducting this study. Our approach to testing this hypothesis is described in the following section.

Methods

The research methodology includes an overview of the complete procedure that the researchers employed based on the study 
(1974) pointed out the relevance of social identities - the identities we form based on our group memberships. Pride about being a current member of a specific group is related to higher self-esteem (Smith \& Tyler, 1997), which makes it harder to see oneself in a very negative light; and having a more positive estimate of group members (Mullen, Brown \& Smith, 1992), makes it harder to see them as people deliberately trying to manipulate others. Being socially responsible and prosocial is related to being more prone to obeying authorities (Passini \& Morselli, 2009). This allows us to hypothesize about the potential mediating role of social ties in the relationship between cognitive distortions and psychological reactance. In this study, we focused on social responsibility, defined as the responsibility that emerges in an individual from recognition of social framework which drives him or her to work for social causes and helps humanity with the environment (Bulmer, 2015).

Rationale

Several studies have been conducted in order to discuss the impact of cognitive distortion in bringing about behavioural changes (Yakovenko et al., 2016; O'Toole, et. al., 2015). These mentioned studies have explored the personal and social context of cognitive distortions that play a major role in developing negative behaviours. It has been observed that individuals, especially men, who are affected by cognitive distortions tend to adopt a behaviours involving conflicts, gambling and violence (Yakovenko et al., 2016). The emergence of distorted thoughts can also result in various other undesirable behavioural changes (O'Toole, et. al., 2015). However, there is only limited literature available about how these rebellious behaviours and psychological rebellion are affected by cognitive distortions with respect to the level of social responsibility. This study is an attempt to gain an in-depth insight into the phenomenon of cognitive distortions that can result in rebellious behaviour of an individual, while in the same time observing how the sense of social responsibility towards the society alters that relationship. This may be especially influential in the field of adolescent delinquency, where both externalizing and internalizing problems were found to be related to psychological reactance (Van Petegem, Soenens, Vansteenkiste \& Beyers, 2015). Defiance and reactance also represent a problem in the field of psychotherapy (Tennen, Press, Rohrbaugh \& White, 1981) and health-promoting campaigns (Clayton et al., 2019), which makes it relevant to study this phenomenon in order to increase their positive effects on the wellbeing of clients. Although the study design is not experimental, its results may promote future researchers to devise experiments that would allow the specification of causal links and the development of strategies to counter both these negative attributions and their behavioural consequences.

Research Objectives

- To study the relationship between the cognitive distortions and psychological reactance.

- To determine the relationship between the cognitive distortions and psychological reactance while taking the impact of responsibility as a mediator variable into account.

\section{Literature Review}

The relationship between psychological reactance and cognitive distortions seems to be relatively complex and bi-directional. Psychological reactance, also known as "counter-control" or "resistance", was recognized as one of the main factors that prevents individuals from disbanding irrational beliefs, which is especially relevant in the field of delusional disorders (Alford \& Beck, 1994). The majority of studies focusing on the relationship between cognitive distortions and reactance came from mental healthcare professionals who had to deal with these issues. 
2016). The relevance of cognitive functioning also highlights the severity of drawbacks caused by its dysfunctions. Cognitive distortions, defined as the emergence of negativity or biases in the thought patterns of an individual which lead to the susceptibility of affecting behaviours (Stallard, 2019; Rnic, Dozois \& Martin, 2016), are one of the forms of dysfunction, which highly affect an individual's capacity to identify, describe, and express emotions (Fang \& Chung, 2019). The paradigm of cognitivism brought mental processes to the forefront as predictors of behaviour (Ertmer \& Newby, 1993), which led to the development of one of the current dominant approaches in psychotherapy, the cognitive-behavioural therapy. This treats cognitive distortions as causes of different maladaptive emotions and behaviours (Fenn \& Byrne, 2013; Samoilov \& Godfred, 2006). One recent study found that even mental problems that emerged through the experience of war by the individuals can be affected by Cognitive Emotion Regulation strategies (Amone-P'Olak, Boitumelo \& Mberengwa, 2019), thus providing clear evidence that this process can also be reversed. However, this process is not straightforward, as not everyone who uses a certain distortion exhibits the same behaviours, indicating that the presence of possible intervening factors (Rnic et al., 2016).

A wide variety of cognitive processes can be biased, some of them related to moral judgements. In psychology, there is a phenomenon called the psychological reactance, according to which individuals choose to opt a rebellious behaviour if they believe that their freedoms have been taken away (Brehm, 1966). Although this judgment does not have to reflect reality (Rnic et al., 2016), it can bring long-term consequences ranging from individuals being less responsive to anti-tobacco commercials because they feel their freedom is being taken away (Clayton, Lang, Leshner \& Quick, 2019) to issues with
HIV-related stigma (Brown, Serovich, Kimberly \& Hu, 2016), diabetes self-care (Gardner \& Leshner, 2015), climate change (Ma, Dixon \& Hmielowski, 2019), and governments informing their citizens about foreign attacks in order to manipulate citizens to join the armed forces (Goddard, 2017). Our estimates of reality especially tend to be biased when there is not enough available information, and it is well-documented that in such situations people tend to base their estimates on available information and create plausible content to fill the gaps in line with the given information, this being called the halo effect (Nisbett \& Wilson, 1977). Some differentiate between the halo and the horn effect, with the halo effect representing a positive bias, while the horn effect represents the negative bias (Burton, Cook, Howlett \& Newman, 2015). Another relevant phenomenon is self-fulfilling prophecy (Merton, 1948, in Biggs, 2009), which reflects a simple notion that people's beliefs influence their behaviour, which makes it more likely that they will behave in a way that will confirm their beliefs. In an extreme example, the combination of these three effects may promote the attribution of stolen freedom to the members of specific group, and form a stereotype that all of them are evil. The group's behaviours promoting this belief make it easy for others to confirm their beliefs and, in the end, turn minor private rebellion into political violence with long-term consequences (Borum, 2003). Thus, cognitive distortions conveyed via narratives or marketing can deliver a great impact on the entire society. Taking this into account, it is crucial to know more about the cognitive biases that can affect psychological reactance in order to improve the success rates of different campaigns and treatments that promote wellbeing and diminish the effects of propaganda that may result in adverse consequences.

However, there are some factors that might affect both cognitive distortions and psychological reactance. For instance, Tajfel 


\title{
Social Responsibility as a Mediator Variable in the relationship between Cognitive Distortions and Psychological Reactance among a Sample of Female University Students
}

\author{
Radeah Mohammed Hamididin \\ Associate professor of Psychology, \\ Department of Psychology \\ Faculty of Arts and Humanities, \\ King Abdulaziz University
}

\author{
By \\ Mogeda El Sayed Aly El Keshky \\ Professor of Clinical Psychology, \\ Department of Psychology \\ Faculty of Arts and Humanities, \\ King Abdulaziz University, Jeddah \& \\ Assiut University, Egypt
}

\begin{abstract}
Normal cognitive functioning enables individuals to ensure the accurate functioning of different thought processes including receiving, selecting, transforming, storing and ultimately retrieving the information which assists a person to navigate respond to the world. Although this navigation may be biased by cognitive distortions, these distortions may also be protected by psychological reactance - a tendency to protect personal liberties that are perceived as being forcefully taken away. In combination, these two phenomena may form a fertile ground for the development of various mental health issues, which highlights the relevance of understanding their relationship.

Aim:To determine the relationship between cognitive distortions and psychological reactance while studying the impact of social responsibility as a mediator variable.

Method: The study was conducted online in a cross-sectional manner, on 328 female Saudi university students recruited from diverse cultural, economic, social backgrounds, who were on average 21.24 years old.

Results: Psychological reactance can be predicted by cognitive distortions, and this relationship is partially mediated by social obligation, while individual responsibility and social response were revealed as suppressors.

Conclusion: Social obligation partially mediated the relationship between cognitive distortions and psychological reactance, however further studies on more representative samples are required before generalizing these results.

Keywords: Psychological reactance, Cognitive distortions, Social Responsibility, University Students.
\end{abstract}

Introduction

Cognitive functioning includes all the mental processes that allow individuals to carry out routine tasks in daily life. It enables human beings to have accurately functioning different thought processes including receiving, selecting, transformation, storing and ultimately retrieving information which assists them in the navigation of and performance of actions in the world (Sternberg \& Sternberg, 